\title{
Lessons From Mixed Dementia
}

With reconsideration of the role of vascular risk factors for Alzheimer's disease (AD; Gorelick et al., 1996), and with a recent Consortium to Establish a Registry for Alzheimer's Disease (CERAD) report that pure vascular dementia may be more difficult to find than has been widely assumed (Hulette et al., 1997), it is appropriate to reevaluate our understanding of so-called mixed dementia, or the dementia syndrome that arises from the combination of $\mathrm{AD}$ and ischemic vascular injuries. Such a reevaluation leads to potentially important lessons, an outline of which is presented here.

\section{VASCULAR RISK FACTORS IN ALZHEIMER'S DISEASE}

Briefly, as reviewed elsewhere, several epidemiologic studies have pointed to the importance of vascular risk factors in all causes of cognitive impairment in late life, including AD (Gorelick, 1997). Most recently, Ott and colleagues (1997) have demonstrated that the presence of atrial fibrillation, even in the absence of stroke, significantly increases the risk of AD. Snowdon and colleagues (1997) have demonstrated that small strokes are associated with both atherosclerosis of the circle of Willis and worse cognitive functioning in elderly nuns who die of $A D$. In addition, clinical studies (Sattel et al.,
1996) have reported that transcranial Doppler sonography of cerebral vessels in patients with $A D$ and multi-infarct dementia suggests the importance of concomitant cerebrovascular disease in the development of cognitive symptoms in both types of dementia. Krauss and colleagues (1996) have shown a significant association between hypertension and idiopathic normal-pressure hydrocephalus, further supporting the idea of the nonspecific, but deleterious, effects of cerebrovascular disease. Apart from the studies of vascular risk factor control by Meyer and colleagues (1985, 1986, 1990, 1995), in which such treatment had a favorable impact on cognitive symptoms in vascular dementia (VaD), but not in $\mathrm{AD}$, studies of treating hypertension in elderly people, where protective, have been protective for both types of dementia.

\section{EPIDEMIOLOGY OF MIXED DEMENTIA}

Against this background, it is not surprising to appreciate that mixed dementia occurs more commonly than would have been expected by chance alone. For example, in the first phase of the Canadian Study of Health and Aging (1994), which probably underestimated the contribution of ischemic vascular injury by 
not routinely requiring neuroimaging of all dementia cases, the prevalence of mixed dementia ( 0.8 cases per 100 people aged 65 and older) was roughly 10 times what would have been expected had mixed dementia occurred merely as the chance product of $\mathrm{AD}$ and $\mathrm{VaD}(0.07$ cases per 100) (Rockwood et al., 1997). Even in the report by Skoog and colleagues (1993) of very elderly subjects (85+ years) in whom supposed incidental cerebrovascular disease might be expected to be common, and in which patients with a typical AD history were reassigned to $\mathrm{VaD}$ based on a positive computed tomographic (CT) scan report, the prevalence of mixed dementia remained twice as high as chance occurrence would have predicted.

\section{DIAGNOSTIC CRITERIA}

There is a considerable variation in current diagnostic criteria for mixed $A D /$ $\mathrm{VaD}$. In the Hachinski Ischemic Score, to which all other $\mathrm{VaD}$ criteria are heir, a score between 4 and 6, however arrived at, was often held to be indicative of mixed dementia (Hachinski et al., 1975). The equivalency of this approach is most evident in the CAMDEX criteria (Roth et al., 1988), but even the newer vascular criteria indicate a great likelihood of $\mathrm{VaD}$ being present when the model is that of multiple infarcts.

In the International Classification of Diseases, 10th revision (World Health Organization, 1992), the condition of mixed $A D / V a D$ does not merit separate consideration, and is combined with the mixed dementia of $\mathrm{AD}$ and metabolic abnormalities, such as thyroid disease or vitamin $B_{12}$ deficiency (Wetterling et al., 1994). Reflecting a view of the sepa- rateness of ischemic lesions and $A D$ pathology, the NINDS-AIREN criteria for $A D$ with cerebrovascular disease requires evidence (clinical or radiographic) of strokes or transient ischemic attacks considered not directly etiologically related to the dementia (Román et al., 1993). The California criteria more logically state that mixed dementia can be diagnosed when one or more other systemic brain disorders are present that can be "... casually related to the dementia" (Chui et al., 1992, p. 476). Mixed dementia nevertheless challenges what we have taken for granted about causality in $\mathrm{VaD}$ (i.e., that the stroke precedes the dementia) by drawing attention to the possibility that whatever may have caused the dementia may also have caused the stroke, so that the temporal ordering may not require the stroke to have come first.

Of the current criteria for mixed dementia, the California criteria (Chui et al., 1992) and the 4th edition of the Diagnostic and Statistical Manual of Mental Disorders (American Psychiatric Association, 1994) (where simply we are asked to record the dementia on Axis I, and $A D$ and stroke on Axis III) seem to have come closest to the broad-mindedness that the subject needs. Nevertheless, both seem to me to rely too much on the stroke model of $\mathrm{VaD}$.

\section{NEUROIMAGING AND PATHOLOGIC STUDIES}

As is well known, neuroimaging studies in AD case series reveal a large number of white-matter lesions (typically in more recent CT scan series) in the range of $44 \%$ (Lopez et al., 1995) to $76 \%$ (Blennow et al., 1991). Magnetic resonance imaging reports are higher, although they appear 
to correspond less well with cognitive impairment (Skoog et al., 1993). If whitematter lesions are considered ischemic, mixed dementia becomes very common indeed. Even if a nonischemic basis for many of these lesions is accepted, the report by Charletta and colleagues (1995) of CT-imaged lacunes in $31 \%$ of patients with presumed $\mathrm{AD}$ challenges the lesser status of mixed dementia. Although neuropathologic confirmation is held as the gold standard in dementia, there are some problems in the interpretation of the occurrence-much less the causal role-of vascular lesions, because such lesions can become inapparent over time. Perhaps this accounts for the inconclusiveness of pathologic findings in mixed dementia. Neuropathologic reclassification can increase or decrease the supposed proportion with mixed dementia, depending on the series. For example, in one of the largest studies (Victoroff et al., 1995), mixed dementia was classified neuropathologically for 25 patients but classified clinically for only 19 patients. Another study (Wade et al., 1987) found that mixed dementia was classified neuropathologically for 10 patients but classified clinically for 16 patients. However, most other studies showed little change (Erkinjuntti et al., 1988; Harrell et al., 1993; Homer et al., 1988; Mölsä et al., 1985).

\section{LESSONS FROM MIXED DEMENTIA}

These data suggest that the diagnosis of mixed dementia represents an important part of the spectrum of ischemic cerebral injury, which in some cases, perhaps on the basis of genetically determined aberrant repair mechanisms, leads to pure $A D$, and which in other cases gives rise to pure $\mathrm{VaD}$. At the very least, it seems that mixed dementia challenges us to reconsider not just how vascular lesions in $\mathrm{AD}$ should be considered, but also how they might be interpreted in VaD. Notwithstanding considerable consensus for positive neuroimaging as a definitive requirement for $\mathrm{VaD}$ (Chui et al., 1992), in many instances these lesions would appear to have little localizing value, and merely signal a brain at risk (Román et al., 1993). If that is so, the risk seems just as important if signaled simply by a long history of hypertension, or by atrial fibrillation (Ott et al., 1997). Similarly, if there is less to the localizing value of strokes in $\mathrm{VaD}$ than has been assumed, it would seem reasonable not to base criteria for $\mathrm{VaD}$ on the multi-infarct model of $\mathrm{VaD}$.

A reconsideration of mixed dementia therefore challenges us, on a practical level, to pay more attention to the operational diagnostic criteria for this syndrome, perhaps recognizing a more broad spectrum of disease between comparatively uncommon pure $\mathrm{AD}$ and pure $\mathrm{VaD}$, and to move away from the multiinfarct model of $\mathrm{VaD}$. A refocus of efforts on understanding the role of vascular risk factors in $\mathrm{AD}$ would seem consistent with a range of other efforts, from use of anti-inflammatory drugs to understanding the role of beta-amyloid in neuronal plasticity, in regarding $A D$ as brain repair gone awry.

\section{REFERENCES}

American Psychiatric Association. (1994). Diagnostic and statistical manual of mental disorders (4th ed.). Washington, DC: Author. 
Blennow, K., Wallin, A., Uhlemann, C., \& Gottfries, C. G. (1991). White-matter lesions on CT in Alzheimer patients: Relation to clinical symptomatology and vascular factors. Acta Neurologica Scandinavica, 83, 187-193.

Canadian Study of Health and Aging. (1994). The prevalence of dementia in Canada. Canadian Medical Association Journal, 142, 1185-1193.

Charletta, D., Gorelick, P. B., Dollear, T. J., Freels, S., \& Harris, Y. (1995). CT and MRI findings among African-Americans with Alzheimer's disease, vascular dementia, and stroke without dementia. Netrology, 45, 1456-1461.

Chui, H.C., Victoroff, J. I., Margolin, D., Jagust, W.,Shankle, R., et al. (1992). Criteria for the diagnosis of ischemic vascular dementia proposed by the State of California Alzheimer's Disease Diagnostic and Treatment Centers. Neurology, 42, 473-480.

Erkinjuntti, T., Haltia, M., Palo, J., Sulkava, R., \& Paetau, A. (1988). Accuracy of the clinical diagnosis of vascular dementia: A prospective clinical and post-mortem neuropathological study. Journal of Neurology, Neurosurgery and Psychiatry, 51, 1037-1044.

Gorelick, P. B. (1997). Status of risk factors for dementia associated with stroke. Stroke, 28, 459-463.

Gorelick, P. B., Nyenhuis, D. L., Garron, D. C., \& Cochran, E. (1996). Is vascular dementia really Alzheimer's disease or mixed dementia? Neuroepidemiology, 15, 286-290.

Hachinski, V. C., Iliff, L. D., Zilhka, E., Du Boulay,G.H., McAllister, V. L., etal. (1975). Cerebral blood flow in dementia. Archives of Neurology, 32, 632-637.

Harrell, L. E., Callaway, R., \& Powers, R. (1993). Autopsy in dementing illness: Who participates? Alzheimer Disease and Associated Disorders, 7, 80-87.

Homer, A.C., Honavar, M., Lantos, P. L., Hastie, I. R., Kellett, J. M., et al. (1988). Diagnosing dementia: Do we get it right? British Medical Journal, 297, 894-897.
Hulette, C., Nochlin, D., McKeel, D., Morris, J. C., Mirra, S. S., et al. (1997). Clinicalneuropathologic findings in multi-infarct dementia. Neurology, 48, 668-672.

Krauss, J. K., Regel, J. P., Vach, W., Droste, D. W., Borremans, J. J., et al. (1996). Vascular risk factors and arteriosclerotic disease in idiopathic normal-pressurehydrocephalus of the elderly. Stroke, 27, 24-29.

Lopez, O. L., Becker, J. T., Jungreis, C. A., Rezek, D., Estol, C., et al. (1995). Computed tomography- but not magnetic resonance imaging- identified periventricular white-matter lesions predict symptomatic cerebrovascular disease in probable Alzheimer's disease. Archives of Neurology, $52,659-664$.

Meyer, J.S., Judd, B. W., Twakina, T., Rogers, R. L., \& Mortel, K. F. (1986). Improved cognition after control of risk factors for multi-infarct dementia. Journal of the American Medical Association, 256, 2203-2209.

Meyer, J. S., Lotfi, J., Martinez, G., Caroselli, J. S., Mortel, K. F., et al. (1990). Effects of medical and surgical treatment on cerebral perfusion and cognition in patients with chronic cerebral ischemia. Surgical Neurology, 34, 301-308.

Meyer, J. S., Obara, K., Muramatsu, K., Mortel, K. F., \& Shirai, T. (1995). Cognitive performance after small strokes correlates with ischemia, not atrophy of the brain. Dementia, 6, 312-322.

Meyer, J.S., Rogers, R. L., \& Mortel, K. F. (1985). Prospective analysis of long term control of mild hypertension on cerebral blood flow. Stroke, 16, 985-990.

Mölsä, P. K., Paljärvi, L., Rinne, J. O., Rinne, U. K., \& Säkö, E. (1985). Validity of clinical diagnosis in dementia: A prospective clinicopathological study. Journal of Neurology, Neurosurgery, and Psychiatry, 48, 1085-1090.

Ott, A., Breteler, M. M. B., de Bruyne, M.C., van Harskamp, F., Grobbee, D. E., et al. (1997). Atrial fibrillation and dementia in a population-based study. The Rotterdam Study. Stroke, 28, 316-321. 
Rockwood, K., Ebly,E., Hachinski, V., \& Hogan, D. (1997). Presence and treatment of vascular risk factors in patients with vascular cognitive impairment. Archives of Neurology, 54, 33-39.

Román, G. C., Tatemichi, T. K., Erkinjuntti, T., Cummings, J. L., Masdeu, J. C., et al. (1993). Vascular dementia: Diagnostic criteria for research studies. Report of the NINDSAIREN International Workshop. Neurology, 43, 250-260.

Roth, M., Huppert, F. A., Tyrn, E., \& Mountjoy, C. Q. (1988). CAMDEX, The Cambridge EXamination for Mental Disorders of the Elderly. Cambridge, England: Cambridge University Press.

Sattel, H., Förstl, H., \& Biedert, S. (1996). Senile dementia of Alzheimer type and multiinfarct dementia investigated by transcranial Doppler sonography. Dementia, 7, 41-46.

Skoog, I., Nilsson, L., Palmertz, B., Andreasson, L.-A., \& Svanborg, A. (1993). A populationbased study of dementia in 85-year-olds. New England Journal of Medicine, 328, 153-158.

Snowdon, D. A., Greiner, L. H., Mortimer, J. A., Riley, K. P., Greiner, P. A., et al. (1997). Brain infarction and the clinical expression of Alzheimer disease. Journal of the American Medical Association, 277, 813-817.

Victoroff, J., Mack, W. J., Lyness, S. A., \& Chui, H. C. (1995). Multicenter clinicopathological correlation in dementia. American Journal of Psychiatry, 152, 1476-1484.

Wade, J. P. H., Mirsen, T. R., Hachinski, V. C., Fisman, M., Lau, C., et al. (1987). The clinical diagnosis of Alzheimer's disease. Archives of Neurology, 44, 24-29.

Wetterling, T., Kanitz, R. D., \& Borgis, K. J. (1994). The ICD-10 criteria for vascular dementia. Dementia, 5, 185-188.

World Health Organization. (1992). The ICD10 classification of mental and behavioural disorders: Clinical descriptions for research. Geneva, Switzerland: Author.

Acknowledgment. Dr. Rockwood was supported by the National Health Research and Development Program through a National Health Scholar Award.

Kenneth Rockwood, MD Division of Geriatric Medicine Department of Medicine Dalhousie University Halifax, Canada 